\title{
Límites y alcances del concepto de Abstracción Real de Sohn-Rethel para un análisis marxiano de la actualidad capitalista desde la óptica de las Nuevas Lecturas de Marx
}

\author{
Lorena Acosta Iglesias ${ }^{1}$
}

Recibido: 1 de mayo de 2020 / Aceptado: 9 de agosto de 2020

Resumen. El propósito de este artículo es exponer la interpretación de la ideología en la obra Trabajo manual y trabajo intelectual. Una crítica de la epistemología (1972) de Alfred Sohn-Rethel entendida como inconsciente del sujeto transcendental, la cual pivota en torno al famoso término abstracción real [Realabstraktion] como principio de síntesis social; $\mathrm{y}$, por otro lado, medir someramente sus alcances y limitaciones respecto de las nuevas lecturas de Marx, concretamente, de la crítica de la escisión del valor [Wertabspaltungskritik]

Palabras clave: Sohn-Rethel; abstracción real; crítica del valor; fetichismo de la mercancía; trabajo abstracto.

\section{[en] Limits and scopes of Sohn-Rethel's concept of Real Abstraction for} a Marxian analysis of current capitalism from the perspective of the New Readings of Marx

\begin{abstract}
The purpose of this article is to expose the interpretation of ideology in the work Intellectual and manual labour. A critique of the epistemology (1972) of Alfred Sohn-Rethel understood as unconscious of the transcendental subject, which is pivoted around the famous real abstraction term [Realabstraktion] as a principle of social synthesis; and on the other hand, to measure some scopes and limitations with respect to the New Readings of Marx, specifically, the critique of the splitting of value [Wertabspaltungskritik].
\end{abstract}

Keywords: Sohn-Rethel; real abstraction; criticism of value, commodity fetishism; abstract work.

Sumario: 1. El surgimiento del concepto de abstracción real como principio de síntesis social en el pensamiento de Sohn-Rethel: significaciones y circunstancias históricas de un concepto central a la par que olvidado en la historia del marxismo; 2. Alcances metodológicos de la posición de Sohn-Rethel desde la perspectiva de las nuevas lecturas de Marx; 3. Límites históricos del diagnóstico de SohnRethel a la luz de las Nuevas Lecturas de Marx; 4. Referencias bibliográficas.

Cómo citar: Acosta Iglesias, L. (2021): "Límites y alcances del concepto de Abstracción Real de SohnRethel para un análisis marxiano de la actualidad capitalista desde la óptica de las Nuevas Lecturas de Marx”, en Revista de Filosofía 46 (2), 419-433.

\footnotetext{
$1 \quad$ Universidad Complutense de Madrid lorenaco@ucm.es
} 
Aprovechando la relativa recién publicación en castellano, gracias a la traducción y edición con estudio introductorio a cargo de Mario Domínguez, de Trabajo manual y trabajo intelectual. Una crítica de la epistemología (1972) de Alfred Sohn-Rethel en Dado ediciones y su también relativo desconocimiento en el ámbito hispanohablante ${ }^{2}$ del estudio actual de contribuciones marxianas ${ }^{3}$, quisiéramos exponer brevemente algunas innovaciones de la lectura de Sohn-Rethel que creemos pertinentes para un análisis marxiano de la actualidad capitalista realizado desde la óptica de las Nuevas Lecturas de Marx, concretamente, de la crítica del valor.

Nos centraremos, principalmente, en su interpretación de la ideología ${ }^{4}$ como inconsciente del sujeto transcendental, la cual pivota en torno al famoso término abstracción real como principio de síntesis social. Este término fue introducido originalmente por Sohn-Rethel en el debate marxista, el cual, como veremos, ha sido repensado en la actualidad por, entre otros, Slavoj Žižek en El sublime objeto de la ideología (1989), cuya interpretación nos ayudará a la hora comprender mejor el término y a su vez medir las distancias, limitaciones y alcances que tendrá originariamente el concepto de abstracción real de Sohn-Rethel con la reinterpretación del mismo en las nuevas lecturas de Marx. Así, en la siguiente cita de la obra principal que aquí trataremos de Sohn-Rethel, se puede observar cómo el filósofo hace hincapié en el plano materialista de la acción que implica el proceso de abstracción como principio de síntesis social a través de la famosa expresión marxiana "no lo saben, pero lo hacen" y que, a su vez, podría ser el motto del concepto abstracción real:

La esencia de la abstracción de la mercancía reside sin embargo en que no está generada por la razón; no tiene su origen en la mente humana, sino en sus actos. Lo cual no proporciona a la "abstracción" un significado estrictamente metafórico. Se trata de abstracción en el sentido más riguroso y literal del término. [...] Aunque los conceptos de la ciencia natural se piensan como abstracciones, el concepto económico de valor

2 Cabe destacar en el ámbito hispanohablante, sin embargo, la investigación de la profesora Chaxiraxi Escuela Cruz (Universidad de La Laguna, Tenerife). Concretamente, los siguientes trabajos, los cuales abordan la postura de Sohn-Rethel en relación con la filosofía adorniana y cuyo acercamiento es realmente valioso para comprender la mutua conformación del pensamiento de ambos autores: Escuela, (2013), (2018) y (2019)

3 Por otro lado, el estudio pormenorizado de esta cuestión no ha sido baladí en otros ámbitos de estudio, como lo es, desde luego, en el panorama intelectual alemán. Allí encontramos numerosos estudios de este concepto de Sohn-Rethel, así como sus alcances y límites, pero desde un punto de vista demasiado interno, diríamos, al debate alemán exegético y no tanto con vistas hacia una reinterpretación para la actualidad -como sí pretenden, por el contrario, las intervenciones a las que aludiremos de Jappe, Postone o Kurz-. Como decimos, han sido más bien tratadas desde un enfoque academicista, eso sí, pormenorizado, de dicho concepto ad intra de los debates que produjo en el siglo pasado (exceptuando la contribución de Helmut Reichelt centrado, justamente, en las nuevas lecturas de Marx). Aún así, consideramos más que pertinente acudir a dichos estudios de los que, a continuación, señalamos una muestra: Paul (2004), Heinz y Hörisch (Hrsg.) (2005), Reichardt, (2008), Engster (2009), Reichelt (2013).

4 Resulta obvio que, dentro del panorama marxista, ha habido muchos autores que se han preocupado por la problemática del estatuto de la ideología en la historia del marxismo, siendo uno de los casos más paradigmáticos, tal vez, el de Terry Eagleton: Eagleton, (2005). Sin embargo, en este artículo quisiéramos centrarnos no tanto en una genealogía exegética de dicho concepto, sino en su reinterpretación desde la crítica del valor, que ya en avanzadilla propuso el propio Sohn-Rethel, de cara a capitalizarlo para un análisis de la sociedad capitalista actual, donde el fetichismo de la mercancía no radica tanto en el encantamiento de la misma, debido al desplazamiento progresivo de la esfera del mercado; sino en la reificación de la relaciones sociales entendiendo el principio de intercambialidad general como principio de síntesis social, algo que, como comentamos, prefigura Sohn-Rethel y desarrollarán más tarde los autores de la crítica de la escisión del valor. 
es una abstracción real. Sólo existe en el pensamiento humano pero no surge de él. Su naturaleza es más bien social y su origen debe buscarse en la esfera espaciotemporal de las interrelaciones humanas. No son los sujetos quienes producen estas abstracciones sino sus acciones. "No lo saben, pero lo hacen". 5

Concretamente, a partir de la exposición de esta interpretación que introdujo Sohn-Rethel, quisiéramos medir someramente sus alcances y limitaciones respecto a la lectura actual de la crítica de la escisión del valor, centrándonos principalmente en Robert Kurz y Anselm Jappe y, por otro lado, en Moishe Postone, quienes centran su análisis marxiano en la reactualización de la teoría del valor y en la vertebración del fetichismo de la mercancía y el trabajo abstracto como principio de síntesis social -algo que prefigura ya tempranamente Sohn-Rethel en su obra y que a su vez distancia a ambas interpretaciones, en cierta medida que más adelante explicitaremos, de la corriente del marxismo tradicional ${ }^{6}-$.

Sin embargo, parte del diagnóstico de la Wertkritik se centra en denunciar la constante ontologización del trabajo abstracto como relación transhistórica con la naturaleza en el marxismo tradicional. Con ello, por otra parte, denunciarán también la reducción del fenómeno de la cosificación centrado únicamente en la esfera del intercambio, ambos puntos de los que no carece precisamente la lectura de SohnRethel. Dicho lo cual, esto sitúa al filósofo de manera ambivalente respecto a su posible capitalización para el análisis de la actualidad capitalista desde la óptica de dichos autores de la Wertkritik ya que, a través de la revolución microelectrónica, se han transformado las formas de organización del trabajo vivo hacia el trabajo inmaterial mediante de la retraducción ideológica de la fuerza de trabajo al capital humano $\mathrm{y}$, por otro lado, la centralidad de la esfera del intercambio se ha visto desplazada por la creciente economía financiarizada.

\section{El surgimiento del concepto de abstracción real como principio de síntesis social en el pensamiento de Sohn-Rethel: significaciones y circunstancias históricas de un concepto central a la par que olvidado en la historia del marxismo}

Sohn-Rethel centra todo su análisis en vislumbrar las bases materiales de la teoría del conocimiento para explicitar el origen materialista de las formas de pensamiento como resultado de las relaciones de dominación y explotación que se perpetúan como forma social del capital a través de la división entre trabajo intelectual y trabajo manual. Un ejemplo de este ejercicio sería la siguiente cita en la que Sohn-

\footnotetext{
Sohn-Rethel, (2017), p. 113. [Cursiva nuestra]

En palabras del propio Moishe Postone, definimos marxismo tradicional como concepto contra el que piensan la actualización de la teoría del valor en la fase posfordista del capitalismo desde la que escriben los críticos del valor. En este sentido, al consistir en una generalización de posturas marxistas sintomatizadas por la centralidad del mercado y la propiedad privada en fases anteriores del capital, en alguna medida, resulta desde luego un concepto útil para repensar el presente a la par que cierto muñeco de paja para repensar el pasado: «Utilizo el término "marxismo tradicional" para referirme a un marco general de interpretación en el que el capitalismo se analiza esencialmente en términos de relaciones de clase basadas en la propiedad privada y mediadas por el mercado. La dominación social es entendida principalmente en términos de dominación de clase y de explotación. Dentro de este marco general, el capitalismo se caracteriza por una creciente contradicción estructural entre la propiedad privada y el mercado (entendido como las relaciones sociales básicas de la sociedad), y las fuerzas de producción (entendidas en términos de trabajo, sobre todo en cuanto trabajo industrialmente organizado)» Postone (2017), p. 85.
} 
Rethel retrotrae -tal vez un tanto de manera aproblemática tal y como le reprochará Horkheimer- el origen del pensamiento abstracto al uso del sistema monetario ya en la antigüedad clásica:

Considerado en su conjunto, el desarrollo social en la historia pasa gradualmente desde el comunismo primitivo, en el que la producción es por entero comunal, hasta la generalización de la producción individual que cubre todas las áreas esenciales y que coincide con el inicio de la producción mercantil. En ese punto, el uso del sistema monetario anuncia la época de la forma social del pensamiento en cuanto intelecto puro separado. La producción manual se convierte en producción simple, al mismo tiempo que el trabajo intelectual se universaliza. Dicho estadio intermedio del desarrollo histórico se alcanzó en la antigüedad clásica y produjo las sociedades esclavistas de apropiación en su forma "clásica" absoluta, las de Grecia y Roma, que excluían a los esclavos de participar en la socialización. ${ }^{7}$

En concreto, Sohn-Rethel se centra en la interpretación de la síntesis transcendental kantiana, «no como acto espontáneo de la conciencia, sino como resultado del proceso de socialización y de abstracción que tiene lugar en la sociedad del intercambio» ${ }^{8}$. De esta manera, nuestro autor se hace con la explicación genética marxiana del método de la crítica de la economía política de la reificación de las relaciones sociales, pero con respecto al apriorismo kantiano como evacuación de todo contenido de origen social, presentándose así ideológicamente como ahistórico. Así en la siguiente cita, Sohn-Rethel problematizará la "espontaneidad" del acto de la síntesis transcendental kantiana como problema, al fin y al cabo, autorreferencial e insuficiente dentro del sistema kantiano; mientras que él propone, por el contrario, vincular el origen de dicha abstracción justamente a la autonomización de la ley de intercambiabilidad general.

Kant estaba en lo cierto al considerar que los componentes básicos de nuestra forma de cognición estaban constituidos a priori y tienen un origen previo, pero se equivocaba al atribuir esta preformación a la propia mente, la cual se dedicaba, según él, a una fantasmagórica "síntesis trascendental a priori”, imposible de localizar ni en el espacio ni en el tiempo. De un modo por entero formal, el sujeto transcendental kantiano contiene rasgos notoriamente similares a la abstracción del intercambio en su destilación monetaria: ante todo por su carácter "originalmente sintético", pero también por su singular unicidad, pues la multiplicidad de monedas reales no puede eliminar la esencial unidad de su función monetaria [...] La cuestión que planteamos sería: ¿cuál es el origen histórico de nuestra capacidad lógica para construir hipótesis matemáticas y qué elemento intervienen en ella? Ni Kant ni ningún otro pensador burgués han seguido de forma consistente esta investigación. En la frase inicial de la Introducción a la segunda edición de la Crítica se aborda el problema pero más adelante se difumina. Kant recoge los factores constituyentes para un principio fundamental "la unidad originariamente sintética de la percepción"; del cual, sin embargo, no ofrece mejor explicación que la de atribuirlo a su propia "espontaneidad trascendental". De este modo, la explicación se transforma en el fetichismo de lo que debe explicarse. ${ }^{9}$

\footnotetext{
Sohn-Rethel, (2017), p. 190.

Escuela, (2013) p. 226.

Sohn-Rethel, (2017), pp. 99, 134 y 135.
} 
Sohn-Rethel comenzó a trabajar en estas cuestiones alrededor del año 1925, fecha en la que coincidió por primera vez con Adorno durante una estancia en Capri, casi una década antes de su primer intercambio epistolar en el año 1936 con Benjamin y Adorno, quienes lucharon por procurarle apoyo económico del Instituto de Investigación Social ${ }^{10}$. Para solicitar dicho subsidio le solicitaron un primer borrador para presentárselo al director del Institut en ese momento, Max Horkheimer, y que luego, muchos años más tarde, conformará el hilo argumental principal de su libro Trabajo manual y trabajo intelectual. Este borrador, conocido como el exposé de Lucerna y titulado Exposé sobre el plan de la teoría sociológica del conocimiento ${ }^{11}$, escrito entre febrero y agosto de 1936 y que sólo será publicado en 1985 como Teoría sociológica del conocimiento ${ }^{12}$, será motivo para una respuesta negativa $-\mathrm{y}$ bastante dura- en una carta de Max Horkheimer a Adorno fechada en 8 de diciembre de 1936 a la petición de subsidio de Sohn-Rethel y respaldada, en último término, por Adorno y Benjamin:

Desafortunadamente, nuestras opiniones difieren de las suyas respecto al trabajo de Sohn-Rethel. Marcuse y yo hemos leído el borrador [el Exposé de Lucerna], aunque solo parcialmente, pero al menos nos creemos capaces de emitir un juicio al respecto. Si la fuerte impresión que le produjeron la carta que le escribió en lugar de un informe y la conversación con él no proviene de otras visiones de Sohn-Rethel diferentes a las que se expresan en el borrador, entonces es usted quien se ha dejado seducir por su gran inteligencia. En la medida en que podemos encontrar algo correcto en la obra, son puntos de vista teóricos que han sido durante mucho tiempo comunes a todos nosotros, presentados en un lenguaje académicamente vanidoso y pomposo. [...] Tengo la impresión de que se ha vuelto ciego frente a la tremenda diferencia entre su propia forma de pensar y la de él, contagiado por la obsesión de la identificación dialéctica, o más bien no dialéctica, de Sohn-Rethel. Su intención de mostrar que el concepto idealista del sujeto está referido a la realidad material puede que coincida con el postulado de una materialización del concepto idealista del conocimiento propio de Sohn-Rethel, pero también puede encontrar tales similitudes formales entre nosotros y nuestros peores oponentes. ${ }^{13}$

De hecho, dada la insistencia tanto de Adorno como de Benjamin, Horkheimer, a pesar de su negativa, propondrá a Adorno, en esa misma carta, la posibilidad de que Sohn-Rethel rehaga otro exposé más breve y conciso por el que se le pagará mil francos. Este segundo borrador titulado Para la abolición crítica del apriorismo. Una investigación materialista (1937), Sohn-Rethel expone, de manera tentativa y no sin dificultades, la intuición que atravesará todo su corpus teórico y que citamos a continuación sintetizada en una pregunta formulada por el propio Sohn-Rethel en dicho borrador:

¿No son quizás la unidad de la conciencia de sí y el sujeto de conocimiento desde el origen, efectivamente, apenas un inevitable reflejo intelectual de la unidad del dinero, el pensamiento discursivo una forma de la conciencia, forma esta debida a la función del

10 Para una mayor contextualización histórica de esta cuestión se remite al estudio introductorio siguiente: SohnRethel, (2007), pp. 17-20.

11 Sohn-Rethel, (2020)

12 Sohn-Rethel, (2002)

13 Adorno y Sohn-Rethel, (1991), pp. 38-39. [Traducción nuestra]. 
dinero para la sociedad mediada por mercancías, y el conocimiento racional del objeto apenas la reproducción ideal de la manera por la cual la producción se realiza en esa sociedad según las leyes del intercambio de mercancías? ${ }^{14}$

Sin embargo, ese carácter hipotético que atravesaba el borrador que le hizo llegar a Horkheimer, fue precisamente aquello que le hizo rechazar por segunda vez la propuesta de Sohn-Rethel, ya que, según el frankfurtiano, no dejaba de tener tintes idealistas como mera traslación o reflejo de la conciencia del proceso material de intercambio de mercancías, cayendo en un mero ejercicio de metábasis, y eludiendo, con ello, el carácter íntimamente dialéctico que sería el adecuado para un acercamiento a categorías idealistas desde un enfoque materialista, algo que ya advertía Horkheimer en la carta citada anteriormente sobre el exposé de Lucerna:

Lo peor es la manera en que la teoría marxiana aparece en el texto. Sostengo que en el lugar de las categorías marxistas podrían estar categorías comteanas, o ciertamente categorías spencerianas, sin que nada se modificase. Sí, ¡aún más! En vez de categorías económicas podrían haber sido introducidas categorías histórico-filosóficas, biológicas o psicológicas. En ninguna parte se hace efectiva la peculiar ironía de las categorías marxianas, en ninguna parte aparece su función crítica, de hecho, las consecuencias ni siquiera se extraen de su contenido económico específico. La teoría marxiana sólo le sirve para ejemplificar lo más radicalmente posible su paso a "concreción», por lo que esto no tiene por qué significar concreta y radicalmente algo tan distinto como ocurre en el caso de los psicólogos de la Gestalt o la fenomenología. ${ }^{15}$

A pesar del rechazo reiterado de su colega Horkheimer, Adorno no cambió de parecer años más tarde sobre la obra de Sohn-Rethel, y así lo explicita tanto en su correspondencia mantenida hasta 1969, año en que murió, así como públicamente en Dialéctica Negativa (1966), donde reconoció de nuevo la importancia del enfoque de su trabajo: «Alfred Sohn-Rethel fue el primero en llamar la atención acerca del hecho de que en el principio transcendental, la actividad universal y necesaria del espíritu, se encierra indiscutiblemente el trabajo social [gesellschaftliche Arbeit]» ${ }^{16}$

\section{Alcances metodológicos de la posición de Sohn-Rethel desde la perspectiva de las nuevas lecturas de Marx}

Efectivamente, si hay algo del enfoque novedoso de Sohn-Rethel que ha pervivido hasta nuestros días, tal como supo ver en su momento Theodor Adorno, es su enfatización en el carácter poiético de las abstracciones del capital en las formas de socialización fetichista que, cristalizadas en la universalidad del intercambio de mercancías, expulsan su carácter procesual histórico y social. En este sentido, para Sohn-Rethel hacer crítica supone explorar las condiciones de posibilidad ${ }^{17}$,

\footnotetext{
Sohn-Rethel, (2007), p. 27.

Adorno y Sohn-Rethel, (1991), pp. 40. [Traducción nuestra]

Adorno, (1984), p. 179.

Efectivamente, la propuesta crítica de Sohn-Rethel se aproxima mucho al concepto de crítica inmanente adorniana como anámnesis de la génesis, esto es: en tanto que toda cosificación supone un olvido de su origen social e histórico, la crítica se encargará de rastrear la génesis sociohistórica por la cual las abstracciones del
} 
entendidas estas como los procesos socio-materiales -haciendo especial énfasis en la explotación ${ }^{18}$ como cesura entre la esfera de producción y consumo y, por otro lado, en la progresiva división del trabajo entre manual e intelectual-, que se encuentran a la base de la formación de las categorías idealistas -especialmente analizadas por Sohn-Rethel aquellas de raigambre kantiana- que rigen la socialización capitalista: concretamente la identidad como forma determinante del pensamiento racional $\mathrm{y}$, al mismo tiempo, como función de equivalente general del dinero.

Respecto a este punto, Sohn-Rethel -al igual que tantos otros de la llamada Escuela de Frankfurt- admite la influencia decisiva de Historia y consciencia de clase de Georg Lukács ${ }^{19}$. El filósofo húngaro, específicamente en el pasaje de las Antinomias del pensamiento burgués, hace un abordaje muy similar del sujeto transcendental kantiano como resultado de la reificación del proceso de abstracción derivado, a su vez, de la progresiva fragmentación social en el taylorismo. Esta se ha debido, por tanto, al aumento de la división social del trabajo a través de la especialización técnica y la expansión del tiempo abstracto del capital -y, a su vez, heredero de la estética transcendental kantiana- que trajo con ello una expansión de dicha reificación del proceso de abstracción a todas las esferas de la vida.

Sin embargo, disintiendo con Lukács, Sohn-Rethel insiste en que la formación del pensamiento racional no es una cuestión meramente de falsa conciencia ${ }^{20}$, como por momentos parece pensar el húngaro ya que, subvertir las relaciones de dominación a través de la conciencia atribuida del proletariado, eliminando con ello la explotación, no rompería de suyo el hechizo del fetichismo de la mercancía. Es decir, Sohn-Rethel, aun cuando se propone vislumbrar las bases materiales del pensamiento idealista con el fin de dar con una teoría del conocimiento materialista que saque a la luz los procesos sociales sobre los que se cimientan la génesis de los conceptos, no cree, contra la postura lukacsiana, que el fenómeno de la cosificación sea un problema eminentemente epistemológico.

Efectivamente, si a algo hace referencia el término abstracción real en la filosofía de Sohn-Rethel es, precisamente, al proceso de intercambio como algo que ocurre en el "plano del hacer" y no en el "plano del saber" y, por tanto, el capitalismo se tiene en cuenta, no como un sistema de producción al margen de lo social, sino especialmente como un sistema de reproducción social total:

capital se han instaurado como estructuras sociales ahistóricas, es decir, reificadas. Cfr. Escuela, (2013), p. 227. Tanto Sohn-Rethel como Adorno parecen tener en mente la famosa cita marxiana que explica sucintamente su concepción genética de la historia en la Introducción a la crítica de la economía política de 1857: «La anatomía del hombre es una clave para la anatomía del mono» Marx, (1972), p. 26

18 «La compulsión sistémica idealista corresponde de hecho a una totalidad, mas no a una totalidad precedente de una síntesis trascendental del sujeto autónomo o de la libertad, sino de su contrario, de la explotación. [...] El formalismo del pensamiento idealista es condicionado por la alienación, provocada en las relaciones sociales entre los hombres por la explotación. La reificación es, en ese sentido una mera determinación formal, en cuanto sirve a la formalización de la explotación.» Sohn-Rethel, (2007), p. 21.

19 «Tenemos en común con Georg Lukács la aplicación del concepto marxiano de fetichismo sobre la lógica y la teoría del conocimiento. Por otro lado, lo que nos distingue de él es que no inferimos del conocimiento del pensamiento racional por la reificación y por la explotación que este pensamiento sea sólo falsa conciencia. En nuestra opinión, ni la lógica ni la reificación irán a desaparecer por medio de la eliminación de la explotación, o sea, en una sociedad sin clases, aún cuando ellas también se modificaran de un modo que no podemos anticipar.» Sohn-Rethel, (2007), p. 22.

20 «En el intercambio de mercancías, el acto y la conciencia de los sujetos recorren caminos diferentes. Sólo la acción es abstracta, la conciencia del actor no lo es.» Sohn-Rethel, (2017), p. 125. 
Toda sociedad formada por una pluralidad de individuos constituye una red que llega a ser efectiva mediante sus acciones. Para esta red social, lo que los seres humanos hacen tiene una importancia esencial y lo que piensan una importancia secundaria. Sus actividades deben estar interrelacionadas para encajar en una sociedad y deben tener un mínimo de homogeneidad para que la sociedad funcione como un todo. Esta coherencia puede ser consciente o no, pero debe existir, de lo contrario la sociedad dejaría de ser viable y los individuos que la componen sucumbirían debido a las múltiples interdependencias establecidas entre ellos. Al usar la expresión "síntesis social” formulo, de un modo muy general, a una de las condiciones de subsistencia de cualquier tipo de sociedad. ${ }^{21}$

Según Sohn-Rethel es en el acto del intercambio ${ }^{22}$, como mediación entre la esfera de producción y consumo, donde aparece la determinación dual de la mercancía como valor de uso y valor de cambio, pudiendo hacerse efectivo el intercambio como principio de síntesis social gracias al equivalente general, esto es, el dinero como abstracción presente que hace posible un proceso real. En este sentido, Sohn-Rethel se deshace de la concepción de la ideología como velo -como falsa concienciatras el cual resplandecería la verdad de los procesos sociales de una sociedad sin clases. Concepción que, dicho sea de paso, no quedó falta de éxito precisamente en la segunda internacional y contra la cual pensó Lukács, aun cuando, probablemente, no de manera suficiente al acabar retomando la concepción de la ideología de nuevo únicamente desde el plano epistemológico. Por el contrario, el economista marxista Sohn-Rethel inclina la balanza hacia la materialidad del proceso de intercambio regido por la abstracción del dinero que, a su vez, ha tenido un progresivo origen histórico - desde Grecia hasta nuestros días-y, por lo tanto, aun cuando pretenda presentarse como dato natural, se muestra con dicha génesis que, si ha llegado a ser así, puede ser de otra manera. Tal y como recupera esta cuestión Žižek en El sublime objeto de la ideología, no se trata del «misterio tras la forma, sino del misterio de esta forma ${ }^{23}$. Efectivamente, Žižek, parafraseando el famoso dictum marxiano "no lo saben, pero lo hacen" 24 , nos plantea la pregunta fundamental -y, por ello, lo sacamos a colación como herramienta hermenéutica- para comprender la transformación del concepto de ideología que opera en la innovación del concepto abstracción real tal y como lo acuña Sohn-Rethel: «¿Dónde está el lugar de la ilusión ideológica, en el "saber" o en el "hacer" de la realidad?»"25

Como hemos adelantado, no se trata de un mero asunto de falsa conciencia, sino que se trata de un proceso real de abstracción, en el cual sólo se reconoce su ser social en tanto reducido a dicha abstracción ${ }^{26}$. Por tanto, la ideología no sería un velo que

21 Sohn-Rethel, (2017), p. 96.

22 «En el intercambio se hace materialmente algo con las cosas, pero este acto está, contradictoriamente, relacionado con la condición de que nada en ellas ocurra materialmente. El acto de intercambio es una actividad física y material y en cuanto tal una negación ejercida positivamente de todo acto que transforma los objetos del intercambio, tanto productivo como de consumo, siempre que la equivalencia deba valer» Sohn-Rethel, (2007), p. 32

23 Žižek, (2003), p. 40.

24 «Al equiparar entre sí en el cambio como valores sus productos heterogéneos, equiparan recíprocamente sus diversos trabajos como trabajo humano. No lo saben, pero lo hacen. El valor, en consecuencia, no lleva escrito en la frente lo que es. Por el contrario, transforma a todo producto del trabajo en un jeroglífico social.» Marx, (1975), pp. 90-91.

25 Žižek, (2003), p. 58.

26 Adelantamos aquí la cita 37 del presente artículo: Cfr. Jappe (2016), p. 15. 
cubre "la verdadera realidad" ni tampoco un sueño o ilusión que construimos para huir de la insoportable realidad de dicho proceso de abstracción; sino que, siguiendo en este punto de nuevo a Žižek, se trata de «una construcción de la fantasía que funge de soporte a nuestra "realidad": una "ilusión" que estructura nuestras relaciones sociales efectivas, reales, y por ello encubre un núcleo insoportable, real, imposible [...] La función de la ideología no es ofrecernos un punto de fuga de nuestra realidad, sino ofrecernos la realidad social misma como una huida de algún núcleo traumático, real..${ }^{27}$

De esta manera, la abstracción de la objetividad social, esto es, en el caso de Sohn-Rethel las leyes del intercambio de mercancías, constituyen tanto el a priori de la producción del siguiente ciclo de reproducción del capital como el inconsciente del sujeto transcendenta ${ }^{28}$ en el que se ha convertido el individuo social, ya que no tiene más remedio que plegarse a las abstracciones que rigen el campo de lo social para entrar en el juego de la socialización. Como podemos observar en la siguiente cita, Sohn-Rethel ahondará en la diferencia entre magnitud del valor y forma del valor que ya estableció Marx en el primer capítulo de El capital de cara a enfatizar el carácter poiético de la última en relación a la sociabilidad posible:

Hemos de tener en cuenta lo importante que es la distinción que establece Marx en su análisis de la mercancía entre "la forma del valor" (o "forma de la mercancía") y la "magnitud del valor". La forma cambiante del trabajo, como trabajo esclavo, trabajo servil y trabajo asalariado y las correspondientes diferencias en la determinación de la magnitud del valor, resultan decisivas para el sistema económico predominante en los diferentes estadios de desarrollo de la producción mercantil. Por el contrario, las características formales invariables del intercambio constituyen un mecanismo de abstracción real indispensable para la síntesis social de principio a fin, proporcionando una matriz del razonamiento conceptual abstracto característico de todas las sociedades basadas en la producción mercantil ${ }^{29}$

Como hemos comentado anteriormente, esta es una de las cuestiones clave que se presenta in nuce en el planteamiento de Sohn-Rethel y que los críticos de la escisión del valor se reapropiarán de cara a reactualizar las herramientas marxianas para el análisis de la actualidad capitalista. Efectivamente, la crítica del valor, concretamente en este caso Kurz, hará hincapié en que «naturalmente, lo fantasmagórico es la dimensión

27 Žižek, (2003), p. 76.

28 Cfr. Žižek, (2003), p. 43. Aun cuando este es el paso que Žižek da más allá del planteamiento de Sohn-Rethel, creemos que dicha tesis se puede ver prefigurada en las siguientes palabras del economista marxista: «A medida que la producción de mercancías se desarrolla y se convierte en la forma típica de producción, la imaginación humana se va separando cada vez más de sus acciones y se va individualizando paulatinamente, llegando con el tiempo a asumir las dimensiones de una conciencia singular. Este fenómeno no se origina en la esfera privada del uso, sino precisamente en la esfera pública del mercado. La conciencia individualizada también está rodeada por la abstracción, pero no es la abstracción del acto del intercambio lo que está en su origen. Puesto que la abstracción de tal acción no se puede observar cuando ocurre, ya que sólo se produce porque la conciencia de sus agentes está absorbida por la transacción y por la apariencia empírica de las cosas pertinentes para su uso, se podría decir que los actores comprenden la abstracción de sus actos porque su propia conciencia se interpone. Si la abstracción llamara la atención de sus mentes, su acción dejaría de ser un intercambio y la abstracción no tendría lugar. No obstante, la abstracción del intercambio sí llega a sus mentes, pero sólo cuando ya se ha consumado por completo dicho evento y se encuentra ante la circulación de mercancías.» Sohn-Rethel, (2017), p. 121.

29 Sohn-Rethel, (2017), p. 151. 
del valor de los productos en cuanto portadores de la "substancia de trabajo" gastada y convertida en algo abstracto. Pues, primero, en cuanto gasto abstracto de energía, la actividad productora no puede separarse realmente de la figura material y sensible del "trabajo concreto". Este proceso, en cuanto automatismo implícito, solo tiene lugar en el inconsciente social que produce la abstracción, aunque en el dinero esa abstracción adquiera realmente forma de cosa $\rangle^{30}$. Esto es, que aun cuando el dinero como equivalente general sea la plataforma "cósica" donde se condensa el valor, la valorización misma entendida como proceso de abstracción que regula, mediante la forma mercancía, todas las relaciones sociales posibles en una sociedad capitalista funciona como inconsciente social del subsiguiente ciclo de valorización, justamente tal y como anticipó Sohn-Rethel, al menos parcialmente, tal y como veremos en el siguiente apartado.

\section{Límites históricos del diagnóstico de Sohn-Rethel a la luz de las Nuevas Lecturas de Marx}

Por tanto, el fetichismo de la mercancía es una inversión real entre lo abstracto y lo concreto $^{31}$, esto es, entre los procesos materiales y las categorías en las que estos se cristalizan y se presentan como naturales. Hasta aquí Sohn-Rethel dio en su momento con una clave fundamental para comprender la forma de dominación anónima del sujeto automático del capital. Sin embargo, este gran avance de Sohn-Rethel respecto del marxismo tradicional, el cual seguía anclado en la concepción de mistificación -de falsa conciencia- que ocultaría las "relaciones reales" de explotación, no deja atrás la concepción clásica del marxismo tradicional del trabajo abstracto como relación transhistórica con la naturaleza y, por ello, para Sohn-Rethel, el origen de la abstracción se encontraría en la convención social inconsciente en la esfera del intercambio, concretamente, en la forma dinero ${ }^{32}$. Así lo formula Anselm Jappe en un artículo en el que tiene por objeto precisamente el origen de la abstracción real en el pensamiento de Sohn-Rethel:

Es incluso posible discutir el "origen" de la abstracción real sin ninguna referencia a la preocupación epistemológica de Sohn-Rethel. La pregunta es: si el capitalismo no es sólo la dominación personal de un grupo social sobre otros grupos, sino que también es el medio por el cual la sociedad en su conjunto es gobernada por abstracciones como el dinero o la mercancía, de dónde vienen esas abstracciones, cuál es su origen: ¿en la esfera de la producción (la esfera del trabajo) o en la esfera de la circulación, la esfera

\footnotetext{
Kurz, (2017) pp. 33 y 34. [Cursiva nuestra]

Cfr. Jappe, A. (2016), p. 17.

«Por eso, no entiende la idea marxista de "fetichismo" como el análisis de las formas fantasmagóricas que asume la mercancía, sino que presta atención a las bases objetivas propias de la sociedad en la que se manifiesta. Lo que descubre en la estructura formal de la mercancía es la existencia de un proceso de abstracción que funciona como "síntesis social", esto es, una universalización de la abstracción mercantil que convierte en conmensurables e idénticos a individuos y acciones que no lo son. Esta síntesis social no se produce por el proceso de trabajo, sino por el del intercambio. Por eso, si bien no niega la abstracción en el proceso de trabajo capitalista, tampoco la entiende como el origen de la síntesis social. Es la mercancía que, al imponerse universalmente, subordina al proceso de trabajo y lo convierte en abstracto. Sohn-Rethel niega que la abstracción surja de la exclusividad en el modo de producción capitalista, si bien con el dinero entendido como un universal intercambiable logra alcanzar un mayor grado de intensidad» Escuela, (2019), p. 525.
} 
del intercambio de los productos del trabajo, la esfera del mercado? Bajo el capitalismo ¿es la actividad productiva misma (el trabajo) la que es alienada o es el acto de vender o comprar el que transforma "inocentemente" productos en mercancías? Esta pregunta no es tan "abstracta" o enrevesada como podría parecer, ya que un asunto importante depende de ella: ¿en qué esfera social debemos intervenir de cara a revertir los estragos generados por la abstracción social? ${ }^{33}$

Esta resistencia de Sohn-Rethel al identificar la abstracción real con la universalidad del intercambio ${ }^{34}$ supone un cierto lastre de cara al análisis de la actual organización social-capitalista pues, como sabemos, esta ha dejado de orbitar en torno a los agentes libres compitiendo en el mercado, dejando atrás el capitalismo liberal y pasando, hoy en día, a la fase de capitalismo posfordista centrado en la economía financiarizada y el trabajo inmaterial ${ }^{35}$ debido a la revolución microelectrónica, la caída del patrón oro y la crisis financiera del 2008. Este cambio de fase del capitalismo ha sacado a la luz el hecho de que su más intima contradicción no puede reposar -contra lo que pretende Sohn-Rethel en último término- en torno a la lucha de clases, ni siquiera en torno

33 Jappe, (2013), p. 7. [Traducción nuestra]

34 Al no tener en cuenta el trabajo abstracto como categoría histórica específica del capitalismo y por tanto, su transformación en valor mediante la medida del gasto de fuerza de trabajo humana en unidades indiferenciadas de tiempo abstracto, Sohn-Rethel tiende a ontologizar la esfera del intercambio al ver en ella el origen de la raíz dual de la mercancía - valor de uso y valor de cambio-y por lo tanto, derivar del proceso de intercambio el efecto homogeneizador de la intercambiabilidad general: «El intercambio contiene un axioma sobre la igualdad de los lotes de mercancías que han de intercambiarse. ¿Cómo podemos definir esta igualdad? [...] Se igualan por el hecho de ser intercambiadas, no son intercambiadas en virtud de alguna igualdad que posean. [...] Para ser más explícitos, la transferencia de las relaciones humanas hacia las relaciones entre cosas o, en otras palabras, la propiedad "reificadora" (Verdinglichende) del intercambio está relacionada con el efecto igualador que el acto del intercambio ejerce sobre los objetos. [...] La contradicción entre la igualdad postulada y la diferencia empírica de las mercancías es tal que no podría emplearse sin la introducción del término "valor", de modo que la igualdad pueda ser considerada como "equivalencia" en relación con el intercambio. Pero el valor no crea la igualdad, sólo se aplica post festum» Sohn-Rethel, (2017), pp. 144 y 145.

35 Es conocida la crítica que realizan los críticos del valor a las posiciones postoperaístas, en las que la transformación de la organización del trabajo vivo en trabajo inmaterial mediante la incorporación de tecnología en el proceso productivo, haría prácticamente imposible diferenciar, según dichas posturas, entre trabajo productivo, trabajo reproductivo y trabajo improductivo, ya que sería imposible, a su vez, determinar el input de tiempo empleado de trabajo vivo debido a la altísima productividad. Sin embargo, como dice Jappe, esto más que suponer un arremetimiento contra la teoría del valor, pone de relieve que el verbo vehicula más que nunca todas las relaciones sociales sin distinción de tiempo de trabajo y tiempo libre. Cfr. Jappe, (2015), pp. 223 y ss. Por otro lado, debido precisamente a la imposibilidad fáctica de determinar la acumulación de trabajo muerto provocada por la revolución microelectrónica, la economía ha tendido a financiarizarse simulando valor en el futuro, por lo que esta es entendida aquí no como la causa de la crisis, sino cómo el efecto del mecanismo de compensación del capital ante la revolución microelectrónica para sobrevivirse como dinámica autotélica y tautológica. Para un profundo análisis de esta cuestión que Kurz denomina el colapso por límite interno de valorización recomendamos acudir a Kurz, (1987). Esto, por otra parte, también es motivo de distanciamiento entre las posturas de Sohn-Rethel y la crítica del valor, ya que, si bien el primero se centra en el posible potencial emancipador de la tecnología -y especialmente, con ella, el modelo de producción que ha posibilitado en el anterior siglo, esto es, el taylorismo- como regulador consciente -y por tanto, presumiblemente socialista- de la reproducción social total a través de la reunión de la actividad intelectual y manual; los críticos del valor, al insistir en la transformación del trabajo en valor ya en la esfera de la producción y no en la esfera del intercambio, son capaces de reconocer en la "nueva economía" que trajo la revolución microelectrónica con su nueva forma de organización del trabajo vivo en trabajo inmaterial únicamente la tensión desnuda entre el proceso de trabajo y el proceso de valorización que se evidencia con la tendencia financiera de la economía a partir de los años 90. Para un desarrollo pormenorizado de esta cuestión en el pensamiento de Sohn-Rethel recomendamos acudir al estudio introductorio de Mario Domínguez en la edición castellana de Trabajo manual y trabajo intelectual. Una crítica de la epistemología: Sohn-Rethel (2017), pp. 56-62. 
a la contradicción (externa) entre capital-trabajo, pues esto supondría que la parte "concreta" del trabajo podría liberarse de cara a organizar socialmente el excedente de plusvalor y dar, de esta manera, con la sociedad sin clases $^{36}$. Sin embargo, aun cuando esto fuera posible, la sociedad todavía se organizaría en torno al concepto de trabajo abstracto, ya que esta es la otra cara del trabajo concreto, entendiendo el concepto de trabajo, no ya como relación ontologizada de metabolismo con la naturaleza tal y como hace aún Sohn-Rethel, sino como categoría específicamente histórica del capitalismo, esto es, siguiendo a Jappe en este punto, como «la reducción efectiva de toda actividad a un simple gasto de energía. Esta reducción es "efectiva" en el sentido de que las actividades particulares -y de igual manera, los individuos que las realizan- sólo se vuelven sociales en cuanto quedan reducidas a dicha abstracción ${ }^{37}$.

Sin embargo, aun cuando, insistimos, Sohn-Rethel, a través de su concepto abstracción real -el cual hay que admitir que se vislumbra, aun cuando no se explicite como tal, en la obra marxiana- da con la forma de reificación como inconsciente social en la que los agentes son meramente "suboficiales" del capital y este se comporta, por tanto, como el verdadero "sujeto automático"; pareciera, por otro lado, que Sohn-Rethel se queda en una comprensión meramente psicológica de tal proceso, pues, como dice Kurz, «al tomar la relación del consumidor con el producto en lugar de las relaciones entre los productores como el objeto de su acción de abstraer, ya en el punto de partida de su deducción de la acción de "abstraer" [en la esfera del intercambio] sucumbe al fetiche cósico del mundo de las mercancías ${ }^{38}$.

Es más, sin caer en la cuenta Sohn-Rethel ${ }^{39}$, ya el propio Marx, en la mencionada Introducción a la crítica de la economía política de 1857, insiste en que la esfera de la circulación no tiene ningún privilegio respecto de la producción, distribución y consumo, sino que son momentos de la totalidad de la reproducción del capital ${ }^{40}$

36 Así parece comprenderlo Sohn-Rethel, ya que diferencia "dos tipos" de trabajo, uno concreto y otro abstracto, cuando más bien se tratan de "dos caras", concreta y abstracta, que inaugura el concepto de trabajo capitalista: «Se denomina al trabajo que produce valor como "trabajo humano abstracto" para diferenciarlo del trabajo concreto que produce valor de uso» Sohn-Rethel, (2017), p. 116.

37 Jappe, (2016), p. 15.

38 «Sohn-Rethel erliegt also schon im Ausgangspunkt seiner Ableitung der "abstraktifizierenden” Handlung dem dinglichen Fetisch der Warenwelt, indem er statt der Beziehungen der Produzenten untereinander die Beziehung des Konsumenten zum Produkt als Gegenstand der Abstraktifizierung nimmt.» Kurz, (1987), p. 85. [Traducción nuestra]

39 O, podría ser, que sí que cayera en la cuenta Sohn-Rethel, pero prefirió pasarlo por alto: «Cabe hacer constar desde el principio que nuestro análisis del intercambio y del valor difiere en ciertos aspectos de los que se encuentran al principio del primer volumen de El capital, sin que ello signifique que contradiga su análisis en esa cuestión. [...] Se podría argumentar, sin embargo, que el análisis marxiano de la mercancía descarta un análisis puramente formal de la abstracción del intercambio, ya que, para Marx, la abstracción del valor siempre se trasmite al trabajo y encuentra su verdadero significado en el trabajo humano abstracto como sustancia económica del valor. [...] Esta convicción personal de que la "forma-mercancía", por emplear la expresión de Marx, puede analizarse como fenómeno en sí mismo, con independencia de las cuestiones económicas, marca una diferencia respecto a la teoría marxiana, pero sólo en el sentido de que se añade a la misma» Sohn-Rethel, (2017), pp. 116, 127 y 129 [Cursiva nuestra]

40 «El resultado al que llegamos no es que la producción, la distribución, el intercambio y el consumo sean idénticos, sino que constituyen las articulaciones de una totalidad, diferenciaciones dentro de una unidad. La producción trasciende tanto más allá de sí misma en la determinación opuesta de la producción, como más allá de los otros momentos. A partir de ella, el proceso recomienza siempre nuevamente. [...] Una producción determinada, por lo tanto, determina un consumo, una distribución, un intercambio determinados y relaciones reciprocas determinadas de estos diferentes momentos. A decir verdad, también la producción, bajo su forma unilateral, está a su vez determinada por los otros momentos» Marx, (1972), p. 20 
cuyo germen se encuentra precisamente en el concepto de trabajo abstracto como gasto de energía medido de unidades indiferenciadas de tiempo empleadas y donde radica, por tanto, la verdadera contradicción capitalista como inversión entre lo abstracto y lo concreto, corazón, a su vez, del fetichismo de la mercancía como vertebración de la socialización capitalista. Así denuncia Postone en la siguiente cita el hecho de que Sohn-Rethel se quedara anclado en la universalidad ontológica del intercambio y no en la transformación del trabajo en valor, lo cual hubiera podido inducir al economista marxista a comprender el concepto de trabajo abstracto en sí mismo como categoría fetichista y, al mismo tiempo, específicamente histórica del capital:

\begin{abstract}
Sohn-Rethel [...] no analiza la especificidad del trabajo en el capitalismo como socialmente constituido sino que, por el contrario, establece dos tipos de síntesis social: uno, el llevado a efecto por los medios de intercambio, y el otro por los medios de trabajo. Argumenta que el tipo de abstracción y el tipo de síntesis social que encierra la forma valor no es una abstracción del trabajo, sino una abstracción del intercambio. Según Sohn-Rethel, existe una abstracción del trabajo en el capitalismo pero se produce en el proceso de producción más que en el proceso de intercambio. Sohn-Rethel, sin embargo, no relaciona la idea de abstracción del trabajo con la creación de estructuras sociales alienadas. En lugar de ello evalúa positivamente el modelo de síntesis social llevado supuestamente a cabo por el trabajo en la producción industrial como no capitalista y lo opone al modelo de socialización llevado a cabo por el intercambio, que evalúa negativamente. ${ }^{41}$
\end{abstract}

Como podemos ver, Sohn-Rethel no pudo ofrecernos una respuesta que llegue hasta nuestros días a la pregunta por la dimensión de reificación de la abstracción real del capital, en gran medida por su aferramiento a la concepción estructural del capital enrocado en la esfera de la circulación, eludiendo con ello su intrínseca dinámica autotélica y tautológica que se desvela con toda su rotundidad en la presente fase del capital que los autores de la Wertkritik han analizado ${ }^{42}$.

41 Postone, (2006), p. 247. Es más, en la siguiente cita, Sohn-Rethel admite explícitamente que no le interesa, para su análisis, la transformación del trabajo en valor (aun siendo la clave fundamental del sistema capitalista) y que por ello se centra en la estructural formal del intercambio de mercancías: «De este modo, la estructura formal del intercambio de mercancías, en cualquier caso particular, permanece idéntica a sí misma durante las diferentes etapas de la producción de mercancías. Me interesa exclusivamente esta estructura formal que no tiene en cuenta la relación entre valor y trabajo.» Sohn-Rethel, (2017), p. 117.

42 Una diferencia fundamental entre el planteamiento de Sohn-Rethel y de la Wertkritik en torno al concepto de abstracción real es que, mientras el primero circunscribe el progresivo proceso de abstracción en torno al intercambio como realidad física que se ejecuta gracias a la abstracción del valor de cambio; los segundos, al centrar su análisis en la inversión entre lo abstracto y lo concreto en la transformación del trabajo en valor, son capaces de cifrar la abstracción real en tanto que la mera sociabilidad se hace posible sólo a través de la abstracción del valor. En este sentido, ahondamos en la anterior cita de Sohn-Rethel para mostrar las distancias mencionadas entre ambas posturas:

«El intercambio implica el movimiento espaciotemporal de las mercancías de propietario a propietario y genera acontecimientos cuya realidad física no es menor que las actividades de uso, a las que descarta. Precisamente, el hecho de que su realidad física vaya a la par es lo que hace que ambos tipos de práctica, intercambio y uso, se excluyan mutuamente a la larga. Es su capacidad de realizarse en el tiempo y en el espacio lo que permite aplicar la abstracción al intercambio; se trata en el sentido riguroso de la expresión de una abstracción real y el "uso" del que se abstrae abarca todo el campo de la realidad sensible [...] De este modo, la estructura formal del intercambio de mercancías, en cualquier caso particular, permanece idéntica a sí misma durante las diferentes etapas de la producción de mercancías. Me interesa exclusivamente esta estructura formal que no tiene en cuenta la relación entre valor y trabajo» Sohn-Rethel, (2017), pp. 122 y 117. 
Pero, por otro lado, cierto es que su gran mérito fue al menos dejarnos la pregunta formulada a través de la que han podido pensar en la actualidad la Wertkritik -en la que aquí más nos hemos centrado, pero también otras Nuevas lecturas de Marx-, cuya inquietud motora uno puede leer entre líneas todavía hoy en las páginas de Das Kapital con ayuda de autores como Sohn-Rethel. El cual, nos proporcionó en su momento, a través de su concepto de abstracción real, la llave a una puerta, cuyo ojo de la cerradura se nos aparece aún con mayor claridad en la actualidad gracias a la reactualización del análisis de la teoría del valor proporcionada en los últimos años: sólo a través de la progresiva abstracción del capital después de los fenómenos ocurridos desde los años 70 hasta la crisis financiera de 2008 como patentes transformaciones del capital que acentúan la dominación de entidades abstractas sobre nuestras cabezas más que a la clásica dominación entre clases ancladas en el concepto de propiedad - de iure capitalista-, ha sido cuando el concepto de abstracción real de Sohn-Rethel ha alcanzado la realidad que pensó, tal vez, por momentos, más allá de la altura de su tiempo.

\section{Referencias bibliográficas}

Adorno, Th. W. (1984): Dialéctica negativa, Madrid, Taurus.

Adorno, Th. W., y Sohn-Rethel, A. (1991): Briefwechsel 1936-39, München, Dialektische Studien.

Eagleton, T. (2005): Ideología: una introducción, Barcelona, Paidós.

Engster, F (2009): "Sohn-Rethel und das Problem einer Einheit von Gesellschafts- und Erkenntniskritik”, Philosophische Gespräche, Heft 15, Helle Panke.

Escuela, C. (2013): "El materialismo como anamnesis de la génesis: la influencia de Alfred Sohn-Rethel en la interpretación adorniana del sujeto trascendental", Constelaciones. Revista de teoría crítica $\mathrm{n}^{\mathrm{0}} 5$, pp. 220-235.

Escuela, C. (2019): "Síntesis social y abstracción idealista. Tentativas materialistas sobre la filosofía del idealismo", Revista Anales del Seminario de Historia de la Filosofía 36 (2), pp. 517-536 [http://dx.doi.org/10.5209/ASHF.58636]

Escuela, C. (2018): "Técnica, intercambio y mundo administrado. Sobre las posibilidades de emancipación social en Adorno y Sohn-Rethel" en M. Cabot, L. Lastória, A. Zuin (eds.), Tecnología, violencia, memoria: diagnósticos críticos de la cultura contemporánea, Barcelona, Anthropos, pp. 55-77.

Heinz, R. y Hörisch, J. (Hrsg.) (2005): Geld und Geltung. Zu Alfred Sohn-Rethels soziologischer Erkenntnistheorie, Würzburg, Königshausen und Neumann.

Jappe, A. (2015): Las aventuras de la mercancía, Logroño, Pepitas de calabaza, 2015.

Jappe, A. (2016): "De lo que es el fetichismo de la mercancía y sobre si podemos librarnos de él" en Marx, K., El fetichismo de la mercancía (y su secreto), Logroño, Pepitas de calabaza, pp. 9-30.

Jappe, A. (2013): "Sohn-Rethel and the origin of "Real abstraktion": a critique of production or critique of circulation?", Historical materialism, n²1.1, pp. 3-14, [http://dx.doi. org/10.1163/1569206X-12341283]

Kurz, R. (2017): "Marx 2000. La importancia de una teoría dada por muerta para el Siglo XXI", Constelaciones. Revista de teoría crítica, n8/9, pp. 28-45.

Kurz, R. (1987): “Abstrakte Arbeit und Sozialismus. Zur Marxschen Werttheorie und ihrer Gesichte”, Marxistische Kritik, nº4, pp. 57-108. 
Marx, K. (1972): Elementos fundamentales para la crítica de la economía política (borrador) 1857-1858 Vol.1, Madrid, S.XXI.

Marx, K. (1975): El capital. Crítica de la Economía Política. El proceso de producción de capital. Libro I, Vol. 1, México, S.XXI.

Paul, A (2004): "Sohn-Rethel auf dem Zauberberg. Über phantastische Ideen, intellektuelle Isolation und den Abstieg der Philosophie zur Wissenschaft” en Ulrich Bröckling, Axel T. Paul, Stefan Kaufmann (Hrsg.): Vernunft - Entwicklung - Leben. Schlüsselbegriffe der Moderne, München, Fink, pp. 73-96.

Postone, M. (2006): Tiempo, trabajo y dominación social. Una reinterpretación de la teoría crítica de Marx, Barcelona, Marcial Pons.

Postone, M. (2017): “La Teoría Crítica del capitalismo". Constelaciones. Revista De Teoría Crítica, 8(8-9), pp. 82-98.

Reichardt, T (2008): “Aporien der soziologischen Erkenntnistheorie Alfred Sohn-Rethels" en Ingo Elbe, Tobias Reichardt, Dieter Wolf (Hrsg.): Gesellschaftliche Praxis und ihre wissenschaftliche Darstellung. Beiträge zur Kapital-Diskussion, Wissenschaftliche Mitteilungen, Heft 6, Hamburg, Argument Verlag, pp. 242-267.

Reichelt, H., (2013): Neue Marx-Lektüre. Zur Kritik sozialwissenschatlicher Logik, Freiburg, Ça Ira.

Sohn-Rethel, A. (2017): Trabajo manual y trabajo intelectual. Una crítica de la epistemología, Madrid, Dado ediciones.

Sohn-Rethel, A. (2007): "Para la abolición crítica del apriorismo: una investigación materialista", Educación superior: cifras y hechos, 33-34, pp. 17-34.

Sohn-Rethel, A. (2002): Soziologische Theorie der Erkenntnis, Suhrkamp, Frankfurt.

Sohn-Rethel, A. (2020): Exposés zur materialistischen Kritik der Erkenntnis. Luzern - Paris - Oxford. 1936-1937 und ergänzende Texte. Schriften III, Freiburg, Ça Ira.

Žižek, S. (2003): El sublime objeto de la ideología, Buenos Aires, Siglo XXI. 